\title{
UMA METODOLOGIA DIGITAL DE PROJETO PARA EDIFÍCIOS EM ALTURA $^{1}$
}
Lilian Maciel Furtado Silva
Centro Universitário de Brasília (UniCEUB) lilianmfs91@gmail.com \\ Neander Furtado Silva \\ Universidade de Brasília (UnB) \\ neander.furtado@gmail.com
}

A METHOD IN DIGITAL DESIGN FOR HIGH-RISE BUILDINGS

\begin{abstract}
Resumo
A projetação ideal de um novo edifício em altura, quando inserido em um contexto urbano existente, não pode ter todos andares idênticos, uma vez que as vistas e condicionantes ambientais mudam de andar por andar, devido às interferências dos edifícios vizinhos e aos ruídos provenientes do trânsito, dos pedestres, etc (DELPINO, 2014). Nossa hipótese de trabalho neste projeto de pesquisa e modelagem em arquitetura foi que é possível projetar um edifício em altura que responda às análises dos condicionantes do terreno e do entorno por meio de mapeamento, andar por andar, considerando ventos predominantes, insolação, intensidade dos ruídos, permeabilidade visual, vistas desejáveis e indesejáveis (DELPINO, 2014). Acreditamos que estes mapeamentos de fachadas, juntamente com a sobreposição dos mesmos, podem constituir instrumentos de análise que fornecem "pistas" de como cada pavimento do edifício em altura pode vir a ser. Estes mapeamentos foram em nossa pesquisa gerados a partir de recursos digitais de modelagem e simulação. Acreditamos também que técnicas de composição e variação, como a Tesselação (IWAMOTO, 2009, p. 35-59; MOUSSAVI, 2009, p. 42216) usada nesta pesquisa podem fornecer as bases formais, estruturais, da escolha de materiais, etc., para este tipo de projeto de edificação.
\end{abstract}

Palavras-chave: Edifício em altura. Projeto digital. Tesselação. Diagramas. Condicionantes ambientais.

\begin{abstract}
A new high-rise building, when inserted in an existing urban environment, cannot have all the floor plans identical since the visual and environmental constraints change from floor to floor due to the interference of neighboring buildings, sun light, prevailing wind and noise. So how can we design a building that takes into consideration all this variables? How can digital design tools help? We believe that a building like that can be designed constructing facade maps which allow a floor by floor analysis considering visual, wind, noise and sun light constraints. We believe that facade maps analysis and their superposition provide clues of how each floor plan can be built to provide comfort and to take most advantage of the view. We believe that variation techniques such as tessellation and morphing can provide the formal bases for such design. We believe that digital design tools are vital both for analysis as well as for designing this type of building.
\end{abstract}

Keywords: High-rise building. Tessellation. Diagrams. Digital design. Environmental conditions.

\footnotetext{
${ }^{1}$ SILVA, L.; SILVA, N. Uma metodologia digital de projeto para edifícios em altura. In: ENCONTRO BRASILEIRO DE TECNOLOGIA DE INFORMAÇÃO E COMUNICAÇÃO NA CONSTRUÇÃO, 7., 2015, Recife. Anais... Porto Alegre: ANTAC, 2015.
} 


\section{的}

\section{TIC2015}

\section{INTRODUÇÃO}

A relação entre um edifício proposto e o seu entorno imediato é uma questão central na projetação arquitetônica. Contudo, esta é frequentemente insatisfatoriamente resolvida ou mesmo negligenciada. $\mathrm{O}(\mathrm{a})$ arquiteto(a) em geral se depara com dificuldades significativas quando projeta um edifício novo para um contexto urbano já existente. Muitas vezes precisa decidir quais condicionantes de projeto irá priorizar e quais irá colocar em segundo plano.

Por exemplo, usufruir de uma bela vista e evitar intensa incidência solar são objetivos frequentemente conflitantes. Com o advento do movimento moderno e do denominado estilo internacional, o uso de pavimentos-tipo se tornou lugar comum em edifícios em altura. Por isto, esta pesquisa, desenvolvida no âmbito do Laboratório de Fabricação Digital e Customização em Massa da FAU/UnB, propõe uma metodologia de projeto que permita a solução diferenciada para cada andar de forma a atender as condicionantes ambientais e também usufruir de vistas desejáveis.

\section{PROBLEMA DE PESQUISA}

A projetação ideal de um novo edifício em altura, quando inserido em um contexto urbano existente, não pode resultar em uma solução em que todos andares são idênticos. As vistas e condicionantes ambientais mudam de andar por andar, devido às diferentes interferências dos edifícios vizinhos e aos níveis de ruídos provenientes do trânsito, dos pedestres, etc, à medida em que se afasta do solo. (Delpino, 2014)

A projetação arquitetônica tem adotado estratégias predominantemente funcionalistas, onde o fator econômico, reduzido à apenas ao seu custo de construção, é considerado o mais importante. Contudo, os impactos ambientais a também geram custos. Por exemplo, edifícios com muitos pavimentos iguais acabam induzindo o uso de ar condicionado em andares mais expostos a alta incidência solar e assim adicionando custos operacionais a longo prazo. Portanto, uma estratégia de projeto de edifícios em altura que seja "sensível" às características variáveis do entorno já existente precisa ser desenvolvida.

\section{HIPÓTESE}

Nossa hipótese de trabalho neste projeto de pesquisa foi no sentido de que é possível projetar um edifício em altura que responda às análises dos condicionantes do terreno e do entorno por meio de mapeamento, andar por andar. Neste sentido consideramos os seguintes condicionantes: ventos predominantes, insolação, intensidade dos ruídos, permeabilidade visual, vistas desejáveis e indesejáveis. (Delpino, 2014) Foi elaborado um mapa para cada um destes condicionantes conforme será apresentado nas seções seguintes.

A justificativa de nossa hipótese reside no fato de que os referidos mapas de fachadas, por condicionante, quando sobrepostos se tornam instrumentos de análise importantes e até mesmo imprescindíveis. Este procedimento permite definir como cada pavimento do edifício em altura pode ser projetado e construído de forma a obter conforto e vistas desejáveis. Nesta pesquisa estes mapas foram gerados a partir de recursos digitais de modelagem tridimensional e simulação.

Nesta pesquisa utilizamos a técnica de Tesselação que consiste em composição e variação de formas geométricas (Iwamoto, 2009, p. 35-59; Moussavi, 2009, p. 42-216), para fornecer as bases formais, estruturais, de escolha de materiais e etc., para este tipo de projeto de edificação. 


\section{MÉTODO DE PESQUISA}

Fundamentamos nosso trabalho no conceito de Tesselação, que por definição parte do princípio de que a forma final a ser criada é construída por repetições de uma ou mais formas geométricas sobre um plano sem que haja espaços entre elas e nem sobreposições.

"Tesselação é a junção de partes que se encaixam sem lacunas para formar um plano ou superfície. Tesselações podem virtualmente ser de qualquer forma desde que as peças se unam em formação compacta." (Iwamoto, 2009, p. 36.)

Um exemplo conhecido de Tesselação são os desenhos metamórficos de M. C. Escher. A aplicação deste conceito em arquitetura pode ser exemplificada pelos murais compostos por azulejos de Portinari e Athos Bulcão. Além disto, malhas definidas digitalmente também podem se constituir em exemplos de Tesselação como visto nos trabalhos de Jorn Utzon e Frank Gehry nas seções seguintes.

Apresentamos a seguir uma imagem de Tesselação conhecida da obra de Escher, que inspirou nosso método de trabalho nesta pesquisa, principalmente na escolha da forma da célula base utilizada na construção de nosso edifício em alturas.

\section{Imagem 1.1 - Metamorfoses de M.C. Escher}

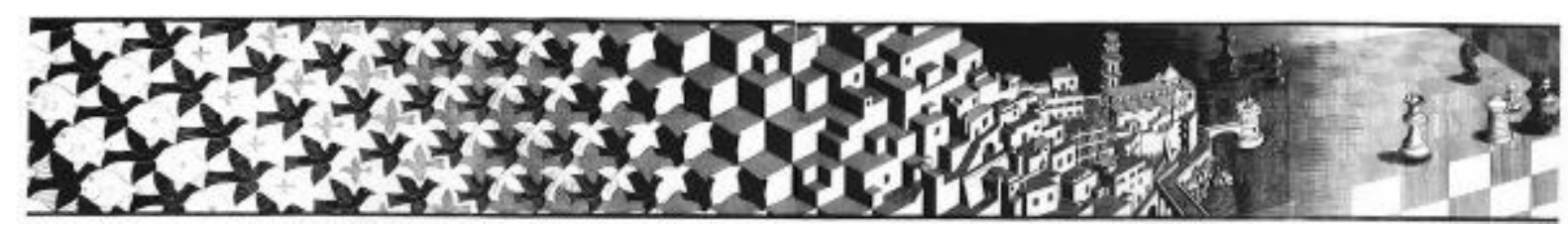

Fonte: http://www.mcescher.com/gallery/transformation-prints/

A Tesselação vem sendo usada na confecção de mosaicos desde a Roma Antiga, Império Bizantino, nas paredes da Arquitetura Islâmica até nos vitrais coloridos das catedrais góticas. Essas superfícies decorativas permitem filtrar a luz ou a vista, definem os espaços, transmitem significado simbólico.

Outro exemplo conhecido de Tesselação, mais simples do que aqueles criados por Escher, são os mosaicos da Roma Antiga, como mostra a imagem abaixo.

Imagem 1.2 - Mosaico de Peixe

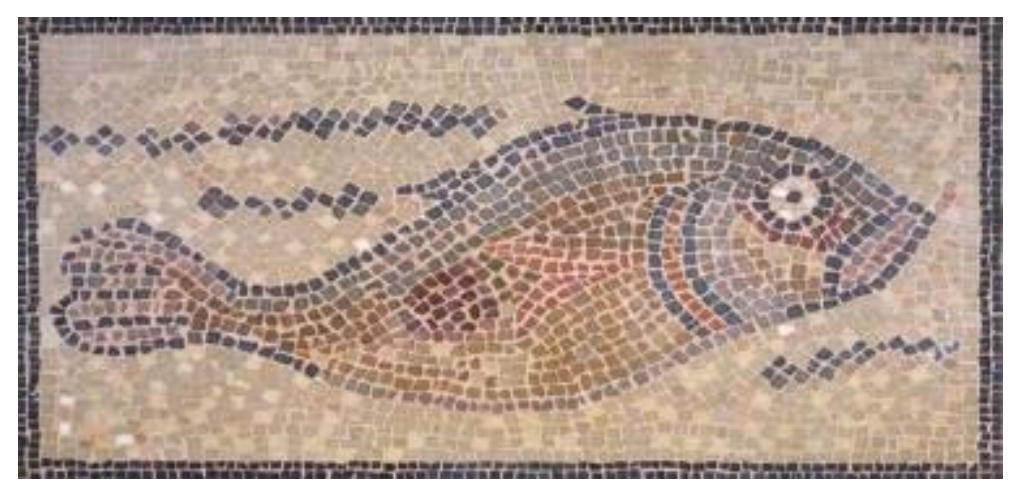

Fonte: www.okeanosgroup.com

Além destes também poderemos citar as formas da cobertura da Ópera de Sydney (1973), projetada por Jorn Utzon. Essas formas foram esboçadas por meio de superfície de segmentos extraídos de esferas de raios variados e depois subdividos em porções planas. Frank Gehry também utilizou outro método de Tesselação, a triangulação, por meio de uma forma facetada na cobertura de vidro do DG Bank (2000) em Parizer Platz, Berlin, Alemanha. (Kolarevic, 2003, P. 45.) 
Imagem 1.3 - Cobertura da Opera House em Sydney

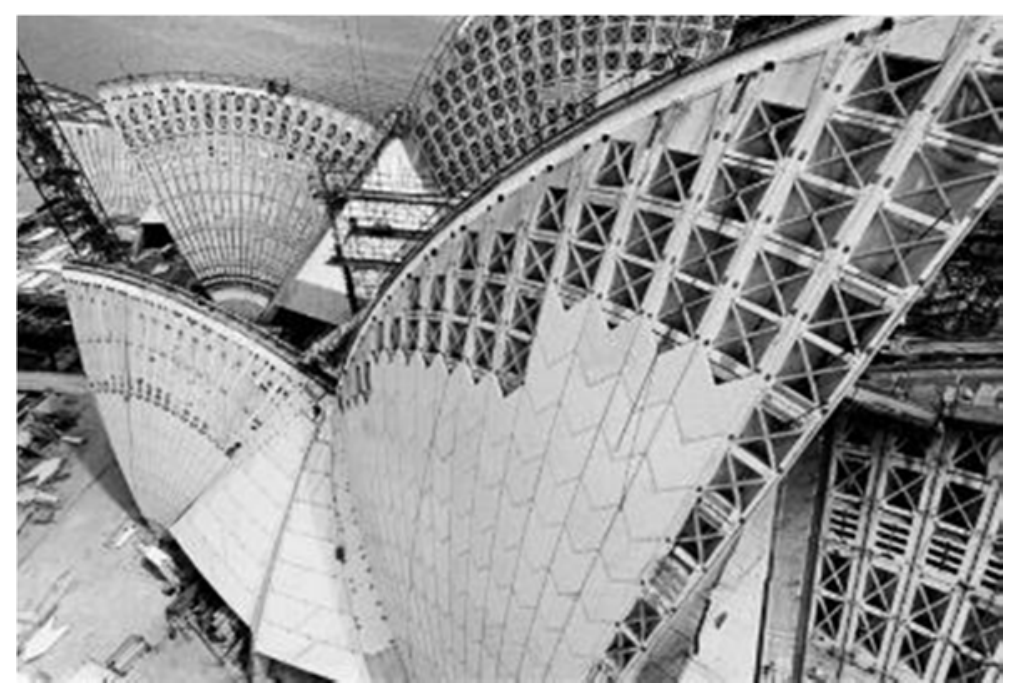

Fonte: https://duranvirginia.wordpress.com/2014/03/13/10-photographers-who-helped-make-architects-famous/ Imagem 1.4 - Cobertura do Pátio de Parizer Platz, Berlin, Alemanha

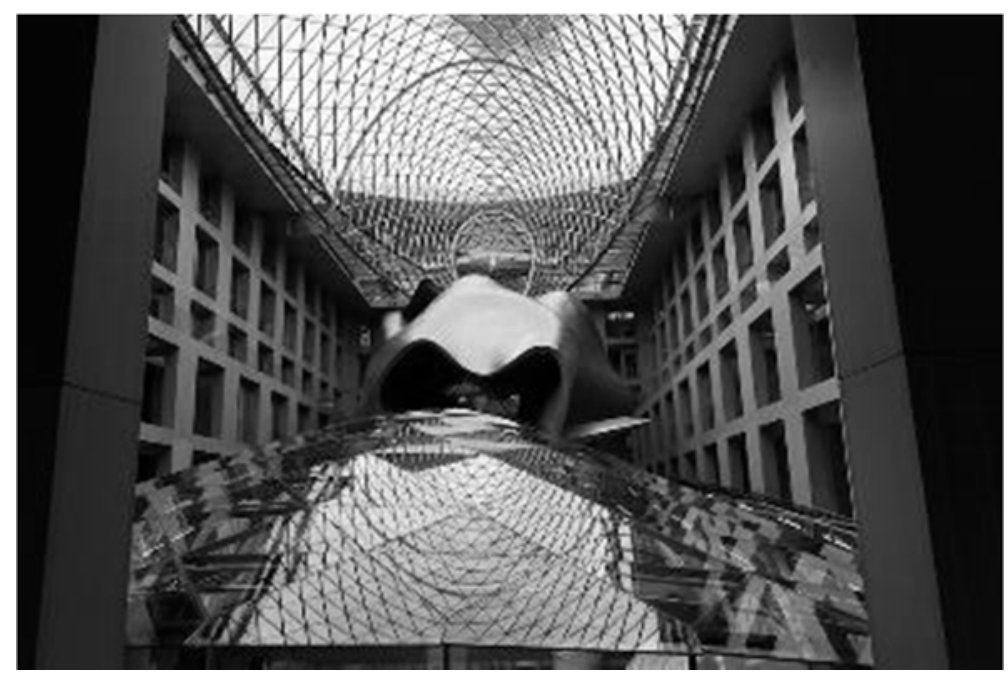

Fonte: http://blaineharrington.photoshelter.com/image/l0000eWUAdKHskMg

Neste trabalho fizemos diversas simulações volumétricas de edifício em altura, a partir de uma malha hexagonal, inspirada na obra de metamorfoses de M. C. Escher. Este autor utilizou o conceito de Tesselação quando desenhou, repetidamente e sem sobreposição, um bando de pássaros voando, cujas figuras transformou gradativamente em formas geométricas e estas, por último, em uma pequena cidade antiga. 
Imagem 1.5 - Inspiração da malha hexagonal da obra do M.C.Escher
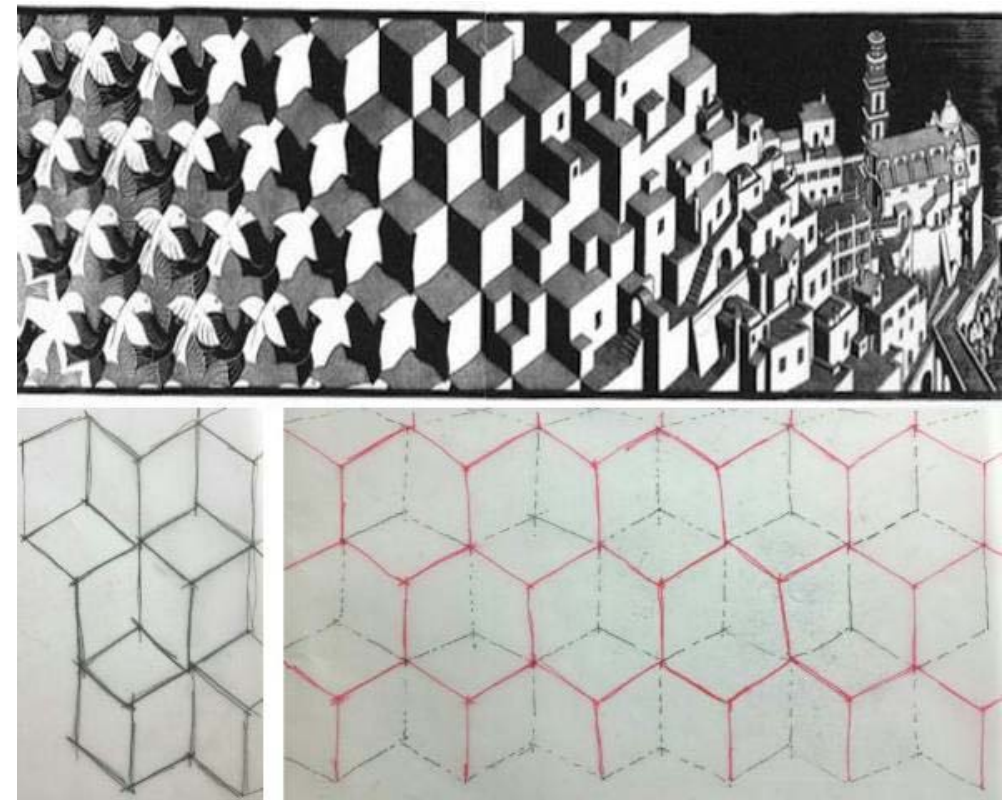

Fonte: autoria nossa.

Segundo nossa interpretação desta obra do M.C. Escher, Metamorfoses III, poderia ter sido feita por meio de tesselações de hexágonos e por isto geramos uma malha hexagonal para projetar o nosso edifício. Geramos volumes hexagonais que seguem essa malha hexagonal para simular as combinações da composição desses volumes.

Imagem 1.6 - Simulações volumétricas a partir da malha

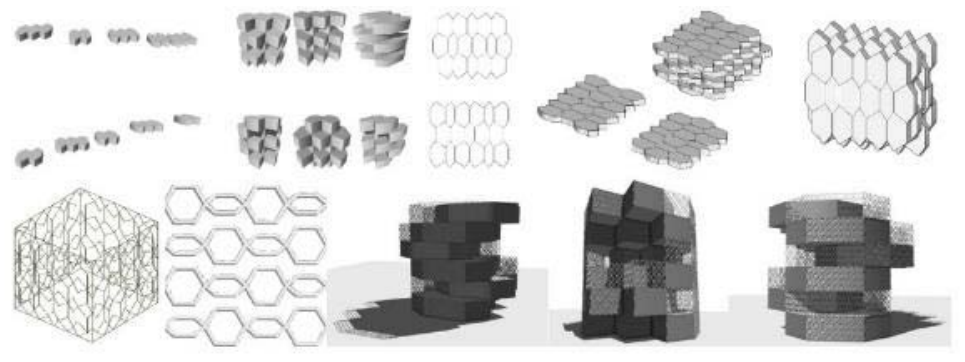

Fonte: autoria nossa.

Analisamos as condicionantes do terreno escolhido no Setor Comercial Sul em Brasília, inserido portanto no contexto urbano, tais como ventos predominantes que vem de leste para oeste, pontos que tem ruídos significantes, vistas consideravelmente desejáveis, indesejáveis e até aquelas obstruídas pelos edifícios do entorno, além da insolação que as fachadas recebem do sol.

Apresentamos a seguir as imagens de todas as fachadas do edifício, mostrando o impacto de cada uma destas variáveis, por grupos de andares. Desta forma é possível visualizar a intensidade de cada uma das variáveis de acordo com a gradação de cores. Nas imagens a seguir, apresentamos o mapeamento de cada condicionante. 
Imagem 1.7 - Análise dos Condicionantes Ambientais terreno escolhido no Setor Comercial Sul em Brasília

LUZ E SOMBRA - RESUMO DA INCIDÊNCIA SOLAR DAS FACHADAS - 8hrs, 10hrs, 14hrs e 16hrs
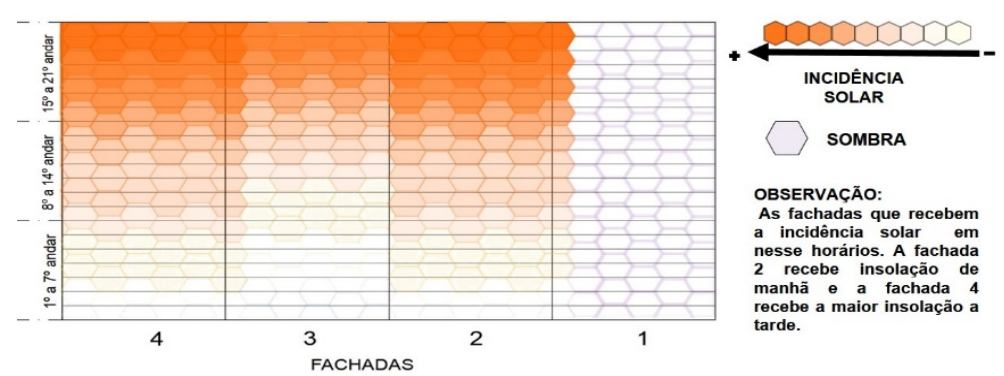

OBSERVAÇÃO:

As fachadas que recebem a incidência solar em
nesse horários. A fachada 2 recebe insolação de manhã $e$ a fachada 4
recebe a maior insolação a tarde.

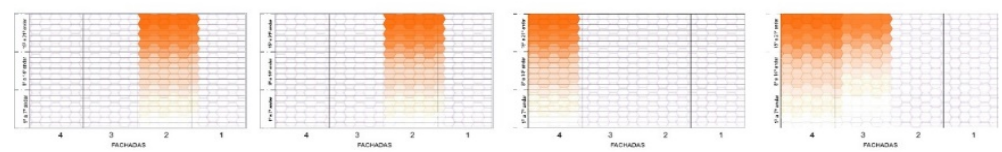

INCIDÊNCIA DE VENTOS PREDOMINANTES NAS FACHADAS
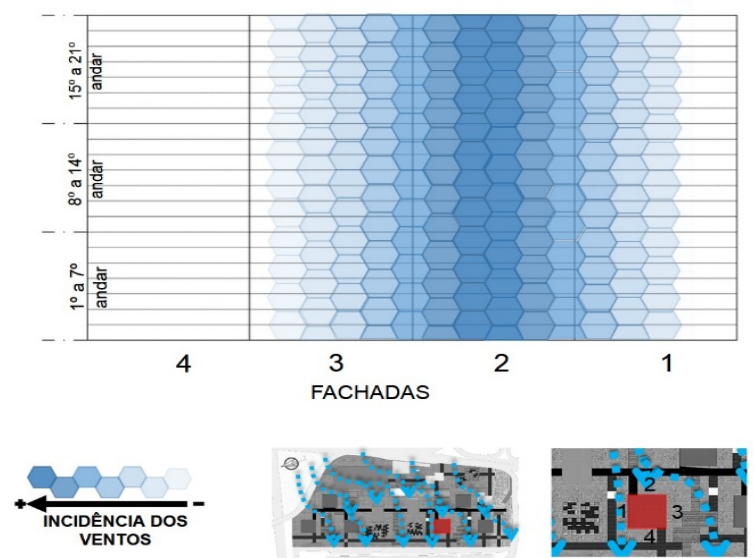

RUÍDOS NAS FACHADAS DO EDIFÍCIO
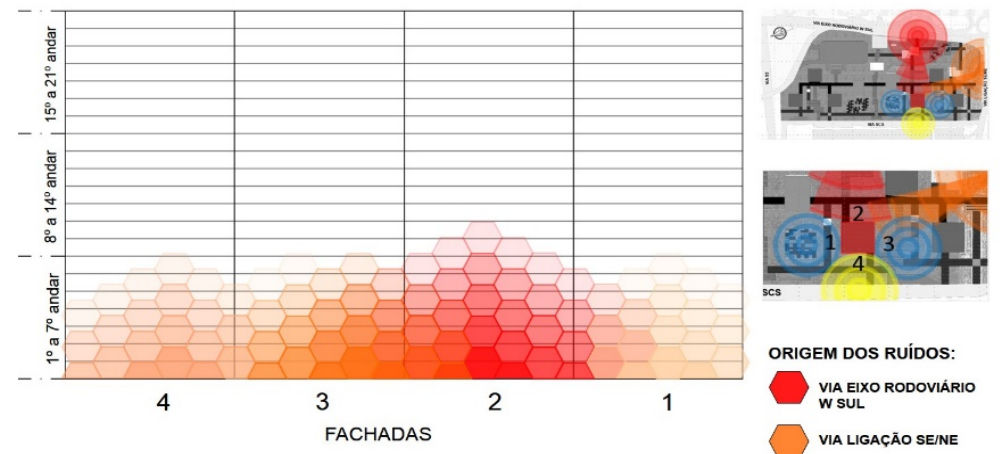

ORIGEM DOS RUÍDOS:

VIA EIXO RODOVIÁRIO
W SUL

VIA LIGAÇÃo SEINE

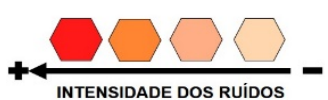

VIA SCS

LOCAIS DE
PERMANENCIA

PERMANENCIA
PROLNGADA MISTA 


\section{TIC2015}

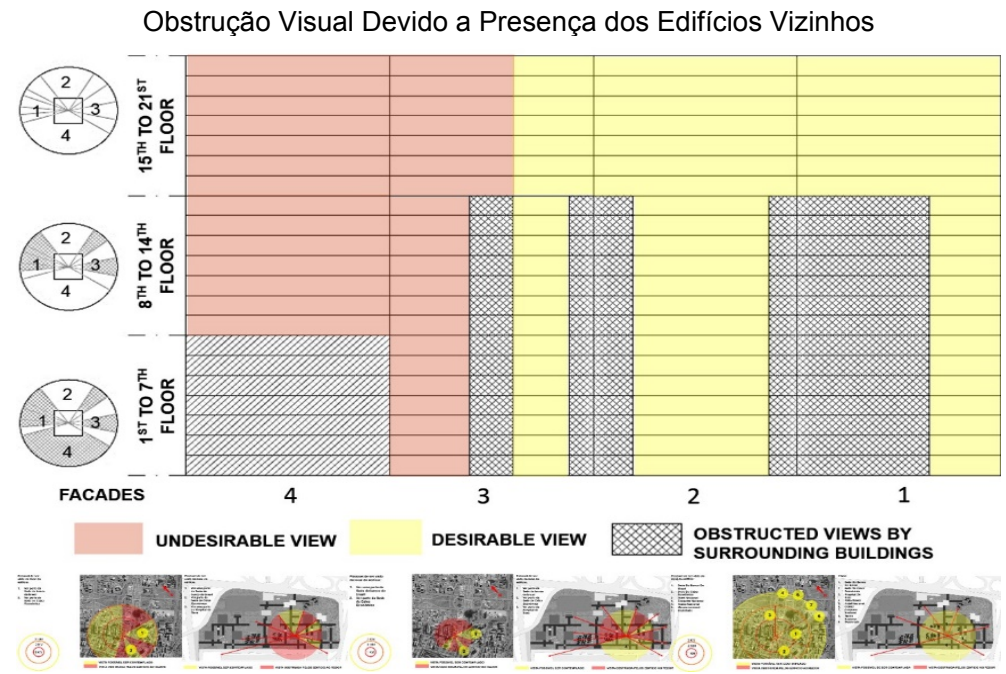

Fonte: autoria nossa.

A seguir fizemos a sobreposição gráfica das análises de cada condicionante referente ao edifício estudado. Nosso objetivo foi identificar os problemas ambientais e vistas desejáveis e propor recomendações para a planta baixa de cada andar do edifício proposto.

Imagem 1.8 - Mapeamento das Fachadas do Edifício Mostrando a Sobreposição das Análises de cada Condicionante Ambiental do Terreno.

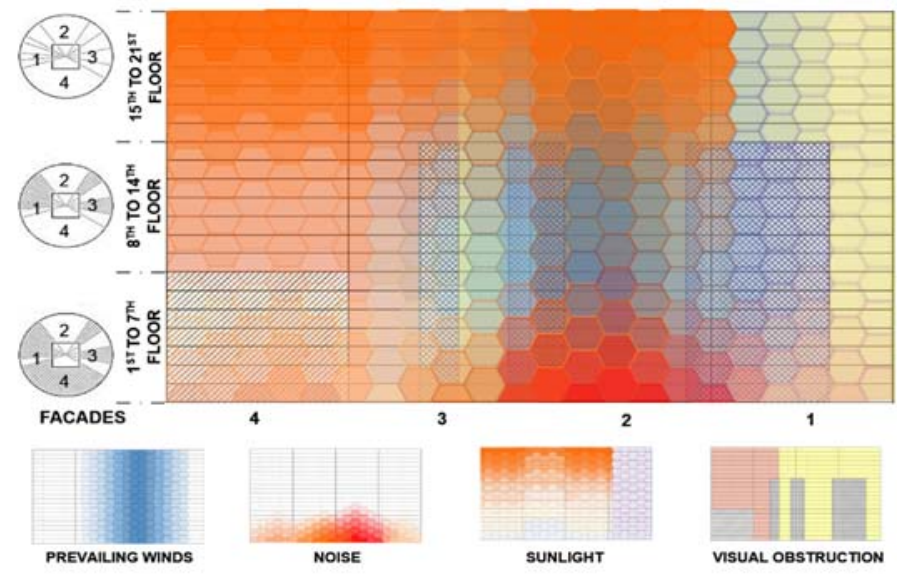

PERMEABILIDADE VISUAL

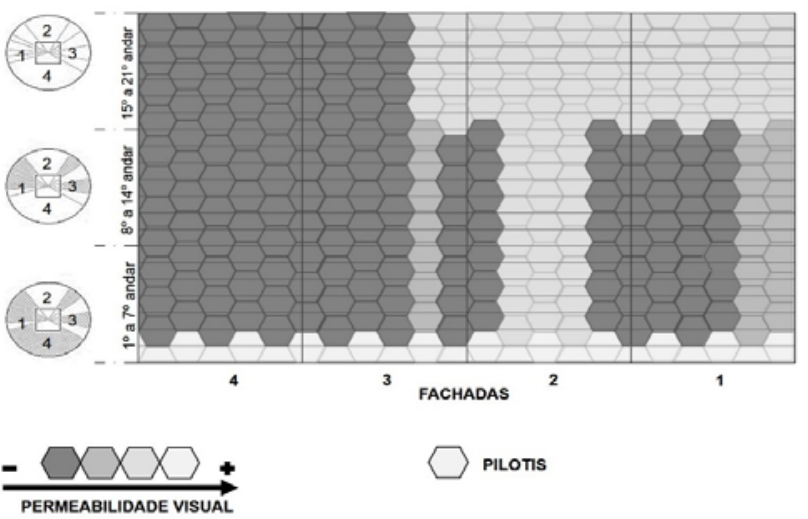

Fonte: autoria nossa. 
Ressaltamos que na imagem a seguir utilizamos duas malhas hexagonais de Tesselação para definir as formas básicas do projeto, no que se refere a composição da forma de cada andar do edifício e a compatibilização das malhas para a elaboração da estrutura. Assim as condicionantes ambientais estão influenciando diretamente a forma de cada andar e por conseguinte a estrutura do edifício.

Imagem 1.9 - Sobreposição das duas malhas hexagonais.

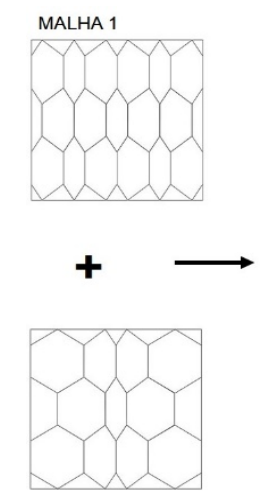

MALHA 2

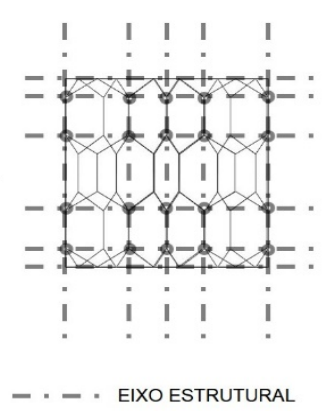

- PILAR

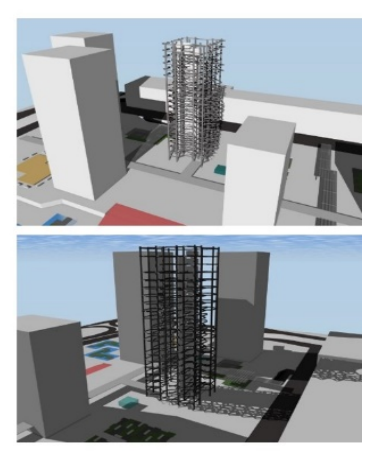

Fonte: autoria nossa.

\section{RESULTADOS}

O resultado deste mapeamento mostrou que existem regiões das fachadas do edifício que recebem simultaneamente pelo menos duas das condicionantes ambientais, em cada andar, com mais intensidade do que as outras.

Imagem 2.0 - Vista de mapeamento das condicionantes do edifício projetado no Setor Comercial Sul, Asa Sul, Brasília, Distrito Federal.

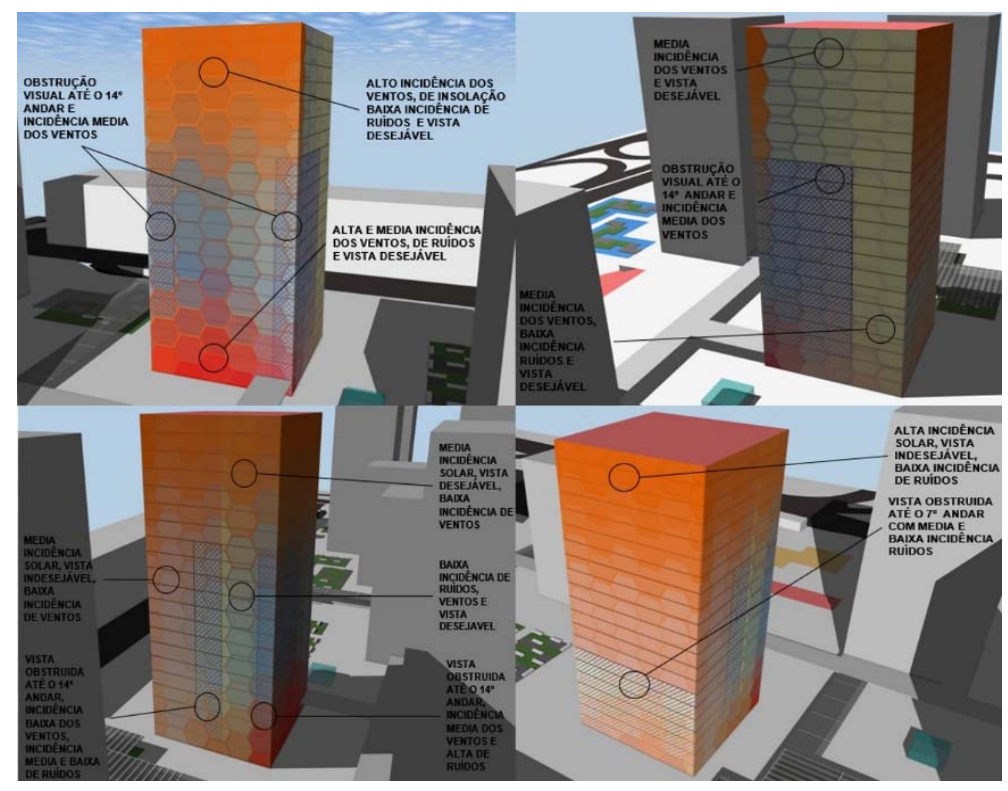

Fonte: autoria nossa. 
Imagem 2.1 - Programa de Necessidades do Edifício com cada andar com planta diferente devido a análise dos condicionantes ambientais.

PROGRAMA
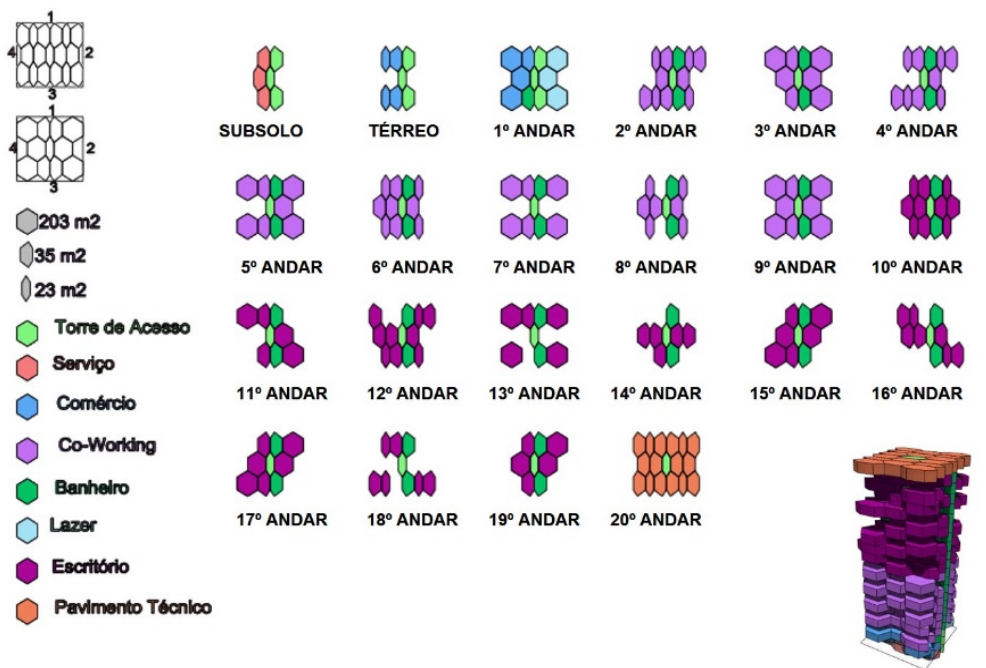

Fonte: autoria nossa.

Por exemplo, a fachada nordeste recebe muito vento e ruídos em pontos específicos. Por outro lado, a fachada sudoeste recebe alta intensidade de insolação. Em relação às outras condicionantes tais como ventos, ruídos, vistas obstruídas e permeabilidade visual a intensidade é considerada média ou baixa. Neste sentido veja a imagem 2.0 que mostra a intensidade destas condicionantes andar por andar.

Utilizamos um software de modelagem tridimensional, FormZ 7.3.4, para projetar e analisar as formas volumétricas no sentido de verificar se elas atendiam às referidas condicionantes ambientais estudadas.

Elaboramos uma escala mostrando desde a intensidade máxima até a mínima para analisar cada condicionante ambiental: exposição a luz solar, ventilação, ruído, permeabilidade visual até as vistas desejáveis de cada andar.

Nesta pesquisa elaboramos diversos diagramas para analisar e mapear cada condicionante isolada e conjuntamente de cada andar e propor uma solução específica para cada um deles. Portanto, em resposta a cada variável estudada propusemos uma planta baixa diferente para cada andar, por meio de adição ou subtração de certa quantidade de células hexagonais das malhas.

Propusemos que soluções arquitetónicas poderiam responder da seguinte maneira: onde houver muita insolação, ruídos e vento retira-se um ou mais células hexagonais, que vem de acordo com a malha de Tesselação hexagonal. Desta forma foi possível criar recuos em alguns andares e áreas que permitem aos usuários usufruir sem quaisquer desconfortos. 
Imagem 2.2 - Soluções Arquitetónicas para os Condicionantes Ambientais. SOLUÇõES PARA CADA SITUAÇÃO

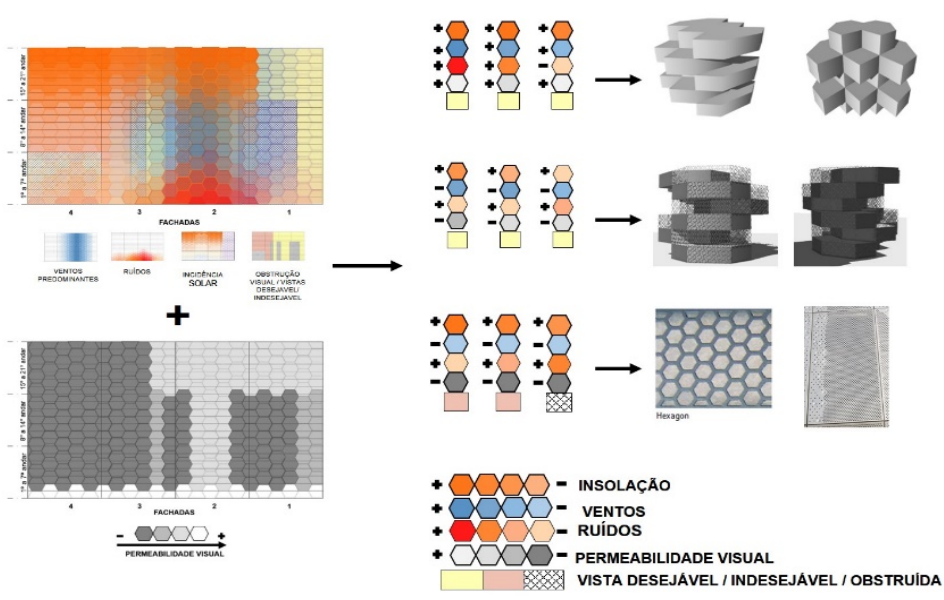

Imagem 2.3 - Modelo 3D e Maquete Física.

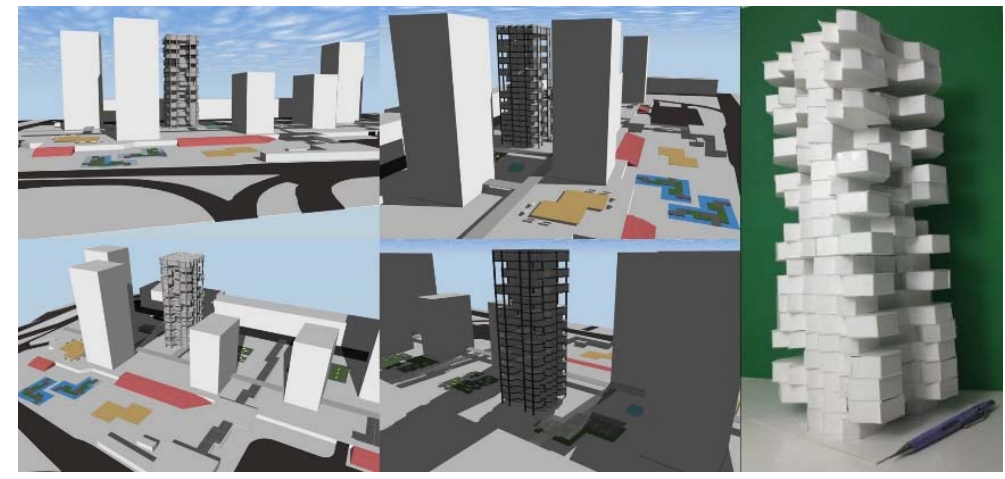

Fonte: autoria nossa.

Em certos andares mantivemos os volumes hexagonais ou até acrescentamos alguns onde há vista desejável para aproveitar. O resultado disto foi que cada andar teve uma planta baixa diferente, respondendo às condicionantes ambientais específicas da edificação.

Considerando os resultados encontrados também pesquisamos uma série de materiais que oferecem mais conforto para o edifício no sentido de reduzir insolação, ruídos e melhorar a ventilação. Nos casos em que a necessidade de um material ou elemento que controlasse melhor as condicionantes de insolação, ruídos e vistas consideradas obstruídas ou indesejáveis pesquisamos materiais como um painel metálico perfurado utilizado em projetos arquitetónicos, da empresa Bausher, no sentido de permitir a luz e o vento passar e bloquear a vista indesejável.

Outra opção seria o uso de uma cortina de Hunter Douglas, do tipo "Alustra $\circledR$ Duette $®$ Architella®", que permite um controle maior de ruídos e de insolação ao mesmo tempo em que preserva e aproveita a vista desejável e interessante dos ambientes projetados de escritório, sala de "co-working", lazer e comercio.

Consideramos também nesta pesquisa a combinação de vidros temperados, do tipo "Low E", que permitem reduzir a insolação juntamente com a cortina de Hunter Douglas em ambientes como escritórios e salas, do tipo "co-working". Desta forma estes materiais combinados contribuem para resolver o problema de insolação e ruídos e ainda usufruir de vista desejável. 


\section{CONCLUSÃO}

Comprovando a nossa hipótese de trabalho, os resultados finais obtidos nesta pesquisa demonstram que é necessário e factível projetar uma solução diferenciada para cada andar de um edifício novo em altura inserido no contexto urbano existente.

Ressaltamos ainda que a maior contribuição nova ao conhecimento apresentada nesta pesquisa consistiu na elaboração de um novo método de projetação utilizando a análise de diagramas individuais e conjunta das condicionantes existentes no contexto da edificação.

Destacamos ainda a importância e relevância da concepção de projeto a partir do conceito de Tesselação e da análise das condicionantes por meio de diagramas e de aplicação dos resultados obtidos na definição da forma da edificação no sentido produzir conforto ambiental.

\section{REFERÊNCIAS}

DELPINO, ROSSANA. Resumo de Curso. UniCEUB, 2014.

IWAMOTO, LISA. Digital Fabrications - Architecture and Material Techniques. Princeton Architectural Press, 2009.

MOUSSAVI, FARSHID. The Function of Form. Harvard University, 2009.

KOLAREVIC, BRANKO. Architecture in the Digital Age - Design and Manufacturing, 2003.

KOLAREVIC, BRANKO. Manufacturing Material Effects: Rethinking Design and Making in Architecture. 2013

SAKAMOTO, Tomoko. From Control to Design - Parametric / Algorithmic Architecture, 2008.

LEE, Franklin. BEAURECUEIL, S. Anne. Articulated grounds: Mediating Environment and Culture. AA Agendas No.7. Architecture Association London. 2009.

KRAUEL, Jacobo. Contemporary Digital Architecture: Design and Techniques. 2010. 